\title{
Effect of Extraction Temperature on Coagulation of Turbid Water Using Peanut Cake as Primary Coagulant
}

\author{
Ahmed H. Birima ${ }^{1}$, Abdulhakim A. A. Binsahaq ${ }^{2}$, Zakaria Che Muda ${ }^{3}$, and Wai Kien Tat ${ }^{4}$ \\ ${ }^{1}$ Centre of Sustainable Technology and Environment, Universiti Tenaga Nasional, Malaysia \\ ${ }^{2}$ Student, Universiti Tenaga Nasional, Malaysia \\ ${ }^{1}$ Centre of Forensic Engineering, Universiti Tenaga Nasional, Malaysia \\ ${ }^{4}$ Department of Civil Engineering Infrastructure Universiti Kuala Lumpur
}

\begin{abstract}
Many researches have been focus on using natural materials as primary coagulants or coagulants aid to replace or supplement chemical coagulants that used widely in the treatment of drinking water. This paper presents study on the effect of extraction temperature on the removal of turbidity from surface water, using peanut cake as primary coagulant. Sodium chloride $(\mathrm{NaCl})$ solution with concentration of 3 mole in one liter of distilled water was used as a solvent to extract the coagulation component from the peanut cake. Synthetic water that made of dissolving Kaolin in tap water was used. Three levels of initial turbidity - 50, 100, and $150 \mathrm{NTU}$ were tested. Three levels of extraction temperature, namely 20,30 and $40{ }^{\circ} \mathrm{C}$ were examined. Results show that turbidity removal was improved with increasing the temperature of the extractor. Results also show that the peanut cake was very effective in removing turbidity from surface water. At $40{ }^{\circ} \mathrm{C}$ of the extraction temperature, the residual turbidity obtained from initial turbidities of 50, 100, and $150 \mathrm{NTU}$ were 8.3, 12.1 and 7.3 NTU respectively. Surprisingly, peanut cake did not drop the pH of water after coagulation.
\end{abstract}

Keywords - Extraction, coagulation, peanut cake, turbidity

\section{Introduction}

Natural coagulants extracted from plants and animals are workable alternatives to synthetic polyelectrolyte as they are biodegradable, safe to human health and have a wider dosage range for flocculation of various colloidal suspensions, as well as cost effective. Natural coagulants have been used to treat drinking water for many centuries. For example, the Nirmali tree produced seeds that were used to clarify turbidity in surface water over 4000 years ago. The Sudanese women discovered clarifying properties in the seeds of Moringa oleifera trees. Other natural extracts that have been reported to have similar traits include tamarind (Tamarindius indica), guar plant (Cyamopsis psoraloides). [1]

A few studies on natural coagulants have been carried out and different natural coagulants were made from plants. For example, Moringa oleifera (MO), Prosopis juliflora and Cactus latifaria. Among plant materials that have been attempted through the years progressed, the seeds from MO have been exhibited to be a standout amongst the best essential coagulants for water treatment. These studies focus on the performance of MO seeds as an option coagulant or coagulant aid for different parts of water treatment, for example, turbidity, alkalinity, aggregate broke down solids and hardness evacuation in crude water. [2]

Abaliwano [3] investigated the effectives of Moringa Oleifera coagulant for the removed of turbidity microscopic life forms and characteristic common matter from surface water. The delayed consequence of this examination shows that in high turbid waters, the evacuations of up to $95 \%$ and at the lower turbid the evacuations of turbidity is $85 \%$. Furthermore, this study demonstrates that the way of water treatment by Moringa Oleifera seed powder coagulant which is the $\mathrm{pH}$ of the coagulant. Despite the way that, the water treated with Moringa Oleifera coagulant was seem to impact the bactericidal action.

Sanchez [4] carried out study about how tannin (Silvafloc) will effect in the surface water treatment based on the coagulants from Quebracho in Italy. Various tests made in this study for evacuation of turbidity, perfect $\mathrm{pH}$ and perfect coagulant measurement. The result turned out with some data firstly, the perfect coagulant measurement of tannin (Silvafloc), the execution of measurements of coagulant depend on the turbidity evacuation and in that study the measurements used was some place around 1 and $29 \mathrm{mg} \backslash 1$. 
Furthermore, a few studies were carried out to investigate the capability of peanut seeds as a natural welldisposed and characteristic coagulant for the treatment of turbid water. The shelled nut seeds have been used after oil extraction; and the component of coagulation was extracted by distilled water and salt solution of different salt concentration. Synthetic water with 200 NTU turbidity was used. Shelled peanut exracted with Nacl (PC-Nacl) could suitably remove $92 \%$ of the 200 NTU turbidity using only $20 \mathrm{mg} / \mathrm{l}$, while peanut seeds extracted with distilled water (PC-DW) could remove only $31.5 \%$ of the same turbidity with the same dose. [5]

The effectiveness of salt extracted peanut seeds in the pretreatment of palm oil mill effluent (POME) was investigated by Birima, et al. [6]. Turbidity, total suspended solids (TSS) and chemical oxygen demand were tested. It has been concluded that, the higher sodium chloride (Nacl) concentration resulted in lower optimum dosage of coagulant and higher percentage of removed for the three constituents tested.

Natural coagulants are preferred in some aspects because of their abundance source, low cost, biodegradation and multifunction. The objective of this study is to investigate the effect of the extraction temperature and the initial turbidity on the coagulation of turbid water, using peanut cake as a primary coagulant.

\section{Materials and methods}

\subsection{Preparation of Peanut Cake Seeds}

The peanut cake was brought from Republic of Sudan. It is a byproduct of the oil manufacturing factory that is always sold in the market to be used as animal feed in the solid form. The peanut cake was crushed to smaller pieces and then grinded to powder using kitchen blender.

\subsection{Preparation of Peanut Stock Solution}

Preparing of peanut stock solution was done carefully. For extraction process, three moles of Sodium chloride $(\mathrm{NaCl})$ were added to the beaker with one liter of distilled water and dissolved to form the $\mathrm{NaCl}$ solution which used as a solvent. After adding $2.5 \mathrm{~g}$ of peanut cake powder to the distilled $\mathrm{NaCl}$ solution, the mixture was mixed using the kitchen blender for 10 minutes. Then the mixture was filtered using tea filter to remove the large particles. Then vacuum pump was used with filter paper of $70 \mu \mathrm{m}$ pore size to get the final solution. However, the stock solution just prepared for one day to be used and can't be kept for more than 24 hours.

\subsection{Preparation of Synthetic water}

Synthetic water was prepared by using kaolin mixed with tap water. Ten grams of kaolin were added to one liter of tap water then the solution mixed at $60 \mathrm{rpm}$ using jar tester for an hour. After that, the mixture was let to settle for 24 hours. The supernatant was decanted into another breaker and it has been used as stock to prepare the required turbidity. The turbidity of this stock was in range of 1700-1800 NTU and it was diluted for different ranges to prepare turbidities of 50,100,150 and $200 \mathrm{NTU}$ [5].

\subsection{Determination of the Required Stock Solution Volume}

The required volume of the peanut stock solution for each particular dosage was calculated according to concentration equation [6] which known by:

Concentration (start) $\mathrm{x}$ Volume (start) $=$ Concentration (final) $\mathrm{x}$ Volume (final)

This equation is commonly abbreviated as:

$\mathrm{C}_{1} \mathrm{~V}_{1}=\mathrm{C}_{2} \mathrm{~V}_{2}$

Where

$\mathrm{C}_{1}=$ concentration of the coagulant in the water, $\mathrm{mg} / \mathrm{l}$

$\mathrm{V}_{1}=$ volume of water to be treated, $\mathrm{ml}$

$\mathrm{C}_{2}=$ concentration of coagulant in stock solution, $\mathrm{mg} / \mathrm{l}$

$\mathrm{V}_{2}=$ volume of stock solution to be added in the beaker, $\mathrm{ml}$

\subsection{Determination of Extraction Temperature}

To investigate the effect of extraction temperature on the performance of peanut cake as a coagulant, three different levels of extraction temperature, namely 20,30 and $40^{\circ} \mathrm{C}$ were tested. To get the temperature of $30^{\circ} \mathrm{C}$ 
and $40^{\circ} \mathrm{C}$, the solvent was poured into a beaker, the beaker was put on top of the hot plate and heated, the temperature was observe using thermometer. When the required temperature was reached, the beaker was removed and the solvent was added to the peanut powder and mixed to obtain the stock solution. For the temperature of $20{ }^{\circ} \mathrm{C}$, the solvent was kept in the room temperature which was in the average of $22{ }^{\circ} \mathrm{C}$ before it added to the peanut cake powder.

\subsection{Coagulation test}

Jar tester (BIBBY Stuart Scientific, UK) was used to carry out the coagulation test. The jar test consisted of three stages: rapid mixing, slow mixing and sedimentation. $500 \mathrm{ml}$ of synthetic water was filled in a one liter glass beaker placed on the slot in the jar tester. During the rapid mixing, the coagulant dosages were added simultaneously into the beakers using pipettes. Rapid mixing time, slow mixing time, settling time, rapid mixing speed, and slow mixing speed were programmed in order to be automatically controlled. Table 1 shows the values of these parameters. After a settling time of 60 minutes, the samples were taken from the beakers. The turbidity of the samples was measured by using Turbidimeter (HACH, Model 2100AN, USA).

TABLE I: Operating variables used for jar test

\begin{tabular}{lc}
\hline Rapid mixing speed (rpm) & $\mathbf{8 0}$ \\
\hline Rapid mixing time (min) & 3 \\
\hline Slow mixing speed (rpm) & 20 \\
\hline Slow mixing time (min) & 15 \\
\hline Settling time (min) & 60 \\
\hline
\end{tabular}

\section{Results and Discussion.}

\subsection{Effect of extraction temperature on turbidity removal}

Figure 1 shows the residual turbidity against coagulant dosage for initial turbidity of 50 NTU with respect to three levels of solvent temperature $20^{\circ} \mathrm{C}, 30^{\circ} \mathrm{C}$ and $40^{\circ} \mathrm{C}$. The residual turbidity with respect to solvent temperature of $20^{\circ} \mathrm{C}$ was $16.5 \mathrm{NTU}$ at its optimal dosage of $15 \mathrm{mg} / \mathrm{l}$ where, the residual turbidity with respect to solvent temperature of $30^{\circ} \mathrm{C}$ was $12.4 \mathrm{NTU}$ at its optimal dosage of $10 \mathrm{mg} / \mathrm{l}$. on the other hand, the residual turbidity with respect to solvent temperature of $40^{\circ} \mathrm{C}$ was $8.3 \mathrm{NTU}$ at its optimal dosage of $15 \mathrm{mg} / \mathrm{l}$.

As initial turbidity of $50 \mathrm{NTU}$ was tested the result shows that within increase the extraction temperature the coagulation with peanut cake improved. Furthermore, six beakers with different amount of peanut dosage were prepared, the first beaker was without coagulant dosage because the settlement level need to be determined. In second beaker $5 \mathrm{mg} / \mathrm{l}$ was not enough to start the coagulation process. In third beaker the coagulant dosage start to do effect where $10 \mathrm{mg} / \mathrm{l}$ was added. However, by increase the amount of peanut dosage the residual turbidity increased because the case of over dosage occurred where adding more coagulant didn't affect any more.

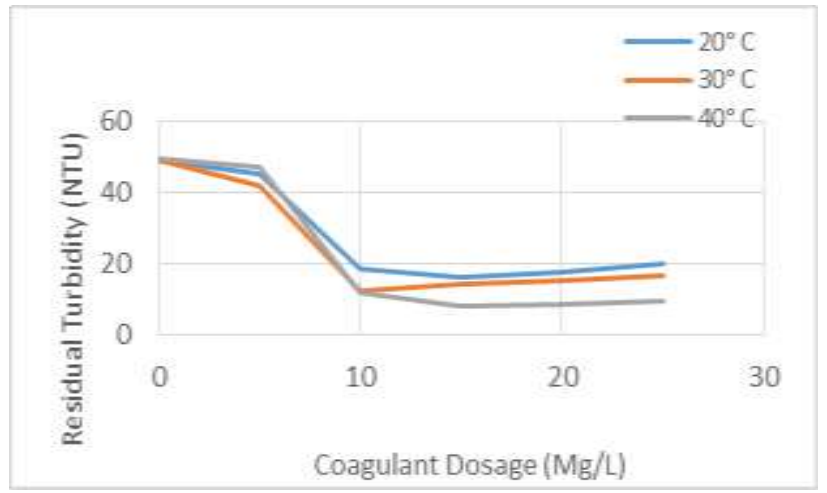

Fig. 1: Residual turbidity versus coagulant dosage for initial turbidity of 50 NTU 
Figure 2, indicates the Residual turbidity versus coagulant dosage for initial turbidity of 100 NTU with respect to three levels of solvent temperature $20^{\circ} \mathrm{C}, 30^{\circ} \mathrm{C}$ and $40^{\circ} \mathrm{C}$. The residual turbidity with respect to solvent temperature of $20^{\circ} \mathrm{C}$ was $14.9 \mathrm{NTU}$ at its optimal dosage of $20 \mathrm{mg} / \mathrm{l}$ where, the residual turbidity with respect to solvent temperature of $30^{\circ} \mathrm{C}$ was $12.2 \mathrm{NTU}$ at its optimal dosage of $25 \mathrm{mg} / \mathrm{l}$. on the other hand, the residual turbidity with respect to solvent temperature of $40^{\circ} \mathrm{C}$ was $12.1 \mathrm{NTU}$ at its optimal dosage of $20 \mathrm{mg} / \mathrm{l}$.

As initial turbidity increased to $100 \mathrm{NTU}$, the three level of extraction temperature was tested and the result shows that with increase the extraction temperature the peanut cake dosage obtained perfect result.

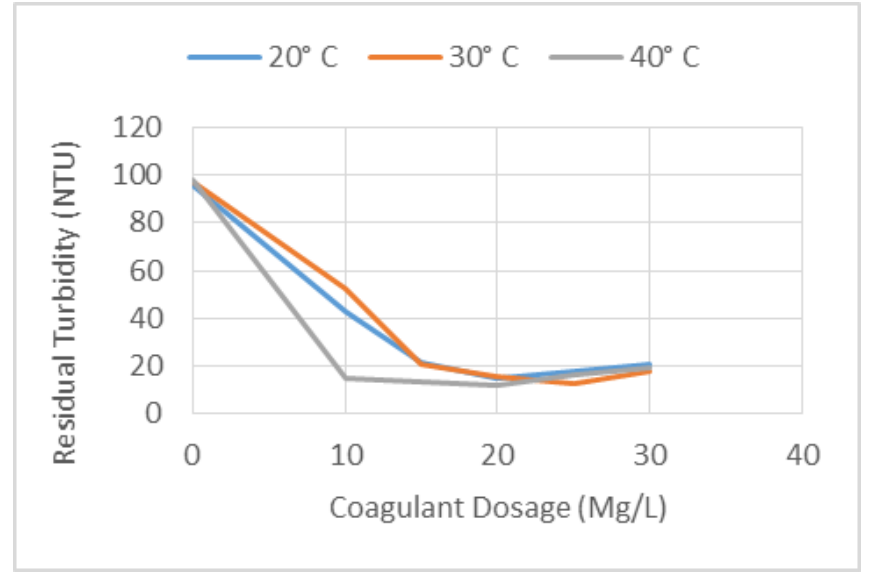

Fig. 2: Residual turbidity versus coagulant dosage for initial turbidity of 100 NTU

Figure 3, shows the residual turbidity against coagulant dosage in initial turbidity (150 NTU) with respect to three levels of extraction temperature $20^{\circ} \mathrm{C}, 30^{\circ} \mathrm{C}$ and $40^{\circ} \mathrm{C}$. The residual turbidity with respect to extraction temperature of $20^{\circ} \mathrm{C}$ was $15.2 \mathrm{NTU}$ at its optimal dosage of $40 \mathrm{mg} / \mathrm{l}$ where, the residual turbidity with respect to extraction temperature of $30^{\circ} \mathrm{C}$ was $12.5 \mathrm{NTU}$ at its optimal dosage of $30 \mathrm{mg} / \mathrm{l}$. on the other hand, the residual turbidity with respect to extraction temperature of $40^{\circ} \mathrm{C}$ was $7.3 \mathrm{NTU}$ at its optimal dosage of $30 \mathrm{mg} / \mathrm{l}$.

Birima, et al. [6] suggested that the protein content in the peanut is responsible of the coagulation activity. From the above results, it is observed that for the three levels of the initial turbidities tested, the turbidity removal increased with increasing the extraction temperature. The reason of this finding could be due to increasing of protein materials with temperature. The impact of temperature on extraction of protein has been observed previously $[7 ; 8]$.

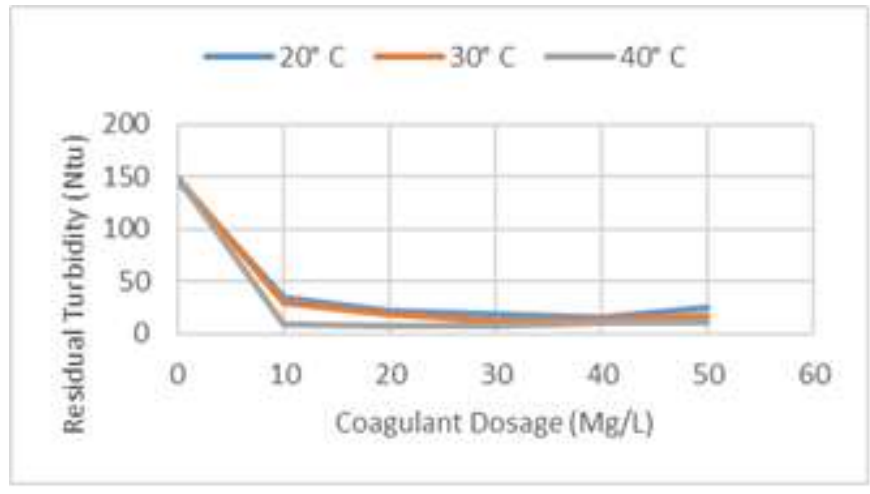

Fig. 3: Residual turbidity versus coagulant dosage for initial turbidity of 150 NTU

\subsection{Effect of Coagulant on the residual $\mathrm{pH}$}

Figure 4 shows the values of initial $\mathrm{pH}$ and residual $\mathrm{pH}$ at the optimum dosage for the three levels of turbidity. It is observed that for the three levels of the initial turbidity tested, the $\mathrm{pH}$ of the water after coagulation was slightly increased with respect to its initial values. Unlike alum, this result shows that using peanut cake as coagulant dose not drop the $\mathrm{pH}$ of the treated water. 


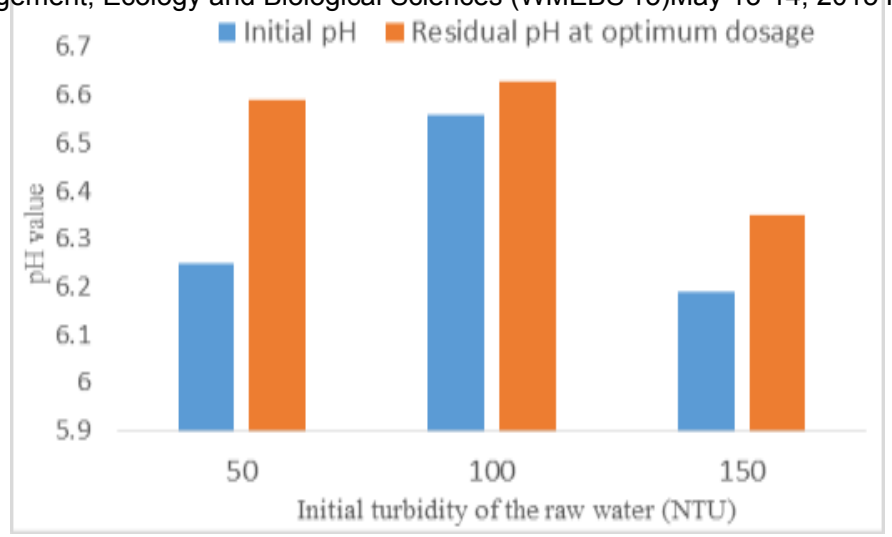

Fig. 4: initial and residual $\mathrm{pH}$ values for at the optimum dosages at different turbidity levels

\section{Conclusions}

The conclusions obtained from this study are drawn as follow:

- The peanut cake has a high potential as primary coagulant in removing the turbidity of the surface water. Thus, for the three levels of the turbidity tested -50,100 and 150 NUT, the optimum dosages of the coagulant were range between $10-15,15-20$ and $30-40 \mathrm{mg} / \mathrm{l}$, and the respective maximum residual turbidity were $8.3,12.1$ and 7.3 NTU.

- Within the limits of the extraction temperature examined, it is found that the removal of the turbidity improved with increasing the temperature of the extractor.

- Peanut did not significantly affect the $\mathrm{pH}$ of the water after coagulation process.

\section{Acknowledgements}

The authors express their gratitude to Universiti Tenaga Nasional, Malaysia who provided the funding for this study under the internal research grant.

\section{References}

[1] S.K. Sharma, R. Sanghi, and A. Mudhoo. Advances in Water Treatment and Pollution Prevention, DOI 10.1007/97894-007-4204-8-1, Springer Science + Business Media, 382-388, 2012.

[2] A. Ndabigengesere, K.S. Narasiah, and B.G.Talbot, Active agent and mechanism of coagulation of turbid waters using Moringa oleifera. Wat. Res., 2: 703-710, 1995.

http://dx.doi.org/10.1016/0043-1354(94)00161-Y

[3] J.K. Abaliwano, Application of the purified coagulant from Moringa oleifera for surface water treatment. Watermill, no.5, pp.701-710, 2008.

[4] M. Sanchez, A laboratory study of moringa oleifera seed extract as a natural coagulant for drinking water treatment. Arch. Appl. sci. res., vol. 3, no. 3, pp. 327-341, 2010.

[5] A.H. Birima, H.A. Hammad, M.N.M. Desa, z.c.Muda, Extraction of natural coagulant from peanut seeds for treatment of turbid water, IOP Conf. Series: Earth and Environmental Science 162 (2013) 012065, 2013.

[6] A.H. Birima, A. T. Ahmed, M.J.M.M. Noor, L.M. Sidek, Z.C. Muda, Application of Salt Extracted Peanut Seeds in the Pretreatment of Palm Oil Mill Effluent (POME), Desalination and water treatment, doi: 10.1080/19443994.2014.930696, 2014.

http://dx.doi.org/10.1080/19443994.2014.930696

[7] G.W. Slling, M.P. Hojilla-Evangelista, R.L. Evangelista, T. Isbell, N. Price, and K.M. Doll, Extraction of proteins from pennycress seeds and press cake. Industrial crops and products vol. 41, pp 113 - 119. 2013.

[8] S. Gupta, G.K. Chandi, D.S. and Sogi, Effect of extraction temperature on functional properties of rice bran protein concentrates. International Journal of Food Engineering vol. 4, 8. 2008.

http://dx.doi.org/10.2202/1556-3758.1165 